\title{
PENGARUH LATIHAN TENDANGAN KE ATAS KURSI TERHADAP KETERAMPILAN TENDANGAN DEPAN PADA EKSTRAKURIKULER PENCAK SILAT DI SMK BINA INSAN MANDIRI
}

\author{
Tatang Suryadin ${ }^{1}$, Udi Sahudi ${ }^{2}$, Kulyana $^{3}$ \\ ${ }^{1}$ Universitas Majalengka, Kab. Majalengka, Jawa Barat, Indonesia \\ ttngsuryadin@unma.ac.id ${ }^{1}$, udisahudi@unma.ac.id², kulyanakul@.gmail.com³
}

\begin{abstract}
This study based on students whose be a part of pencak silat extracurricular that during the front kick technique incorrectly. due to question of consider, is there an effect of kick training on a chair on front kick skills in pencak silat extracurricular at SMK Bina Insan Mandiri? And the purpose of the study was to determine the effect of kick training on a chair on front kick skills in pencak silat extracurricular at SMK Bina Insan Mandiri. The research method used was experimental with Pre-Experimental Design in the form of one group pretest posttest. The population and sample are students who take extracurricular pencak silat at SMK Bina Insani, totaling 16 people taken by total sampling. this test of study used was a kick skill test that was adapted from Lubis and Wardoyo. Data analyze of using paired sample $t$ test. Based on process this data shows us there was an increase of 4.125 , with a standard deviation of 0.719. Sig value (2-tailed) obtained a value of 0.000. that can be conclude, the sig value is smaller than the alpha value $(0.000<0.05)$. So, it can be concluded that there is an effect of kick training on a chair on front kick skills in extracurricular pencak silat at SMK Bina Insan Mandiri. The researcher recommends the upchair kick basic exercise as an alternative to train and improve the front kick technique.
\end{abstract}

Keywords: The Front kick, chair as obstacle, and effective efficient

\begin{abstract}
ABSTRAK. Dasar dalam penelitian ini adalah siswa yang mengikuti ekstrakurikuler pencak silat keseluruhan dalam melakukan tendangan depan teknik nya masih kurang benar. Dengan rumusan masalah apakah terdapat pengaruh latihan tendangan ke atas kursi terhadap keterampilan tendangan depan pada ekstrakurikuler pencak silat di SMK Bina Insan Mandiri? Dan tujuan penelitian untuk mengetahui pengaruh latihan tendangan ke atas kursi terhadap keterampilan tendangan depan pada ekstrakurikuler pencak silat di SMK Bina Insan Mandiri. Metode penelitian yang digunakan eksperimen dengan Pre-Experimental Desain dalam bentuk one group pretest posttest. Populasi dan sampel adalah siswa yang mengikuti ekstrakurikuler pencak silat di SMK Bina Insani yang berjumlah 16 orang diambil dengan cara total sampling. Tes yang digunakan adalah tes keterampilan tendangan diadaptasi dari Lubis dan Wardoyo. Analisis data menggunakan paired sample $t$ test. Berdasarkan pengolahan data diperoleh terjadi peningkatan sebesar 4,125, dengan standar deviasi 0,719. nilai Sig. (2-tailed) diperoleh nilai 0.000 . Oleh karena nilai sig lebih kecil dari nilai alpha $(0,000<0.05)$. Jadi bisa disimpulkan terdapat pengaruh latihan tendangan ke atas kursi terhadap keterampilan tendangan depan pada ekstrakurikuler pencak silat di SMK Bina Insan Mandiri. Peneliti merekomendasikan latihan tendangan ke atas kursi sebagai alternatif untuk melatih dan memperbaiki teknik tendangan depan.
\end{abstract}

Kata Kunci: tendangan depan, kursi sebagai rintangan dan efektif efisien.

\section{Pendahuluan}

Tendangan adalah salah satu teknik yang sering digunakan dalam pertandingan pencak silat. Tendangan sangat efektif untuk menyerang maupun mematahkan serangan lawan. Tendangan juga memiliki nilai yang lebih tinggi dibandingkan dengan serangan tangan serta memiliki jangkauan yang lebih jauh. Tendangan juga sangat mudah dilakukan dan dikombinasikan dengan jenis serangan-serangan lainnya. 
Jadi tidak salah apabila teknik tendangan menjadi perhatian dari para pelatih pencak silat kategori tanding. Berbagai cara latihan diciptakan untuk meningkatkan performa dari tendangan para atlitnya.

Teknik tendangan depan merupakan tendangan paling mudah dilakukan. Tendangan ini dilakukan dengan cara diangkat salah satu kaki baik kaki kanan ataupun kaki kiri lalu menendang dengan posisi kaki lurus kedepan jari-jari kaki menghadap keatas dengan hentakan menggunakan telapak kaki khususnya telapak kaki bagian belakang dengan hentakan teloapak kaki sejajar dengan bahu dan maju kedepan dengan hentakan telapak kaki kearah lawan. Tendangan depan adalah serangan yang menggunakan kaki dan tungkai lintasan nya ke arah depan dengan posisi badan menghadap ke depan dengan perkenaannya pangkal jari-jari bagian dalam atau tumit dengan sasaran ulu hati (Lubis \& Wardoyo, 2004)

Siswa yang mengikuti ekstrakurikuler pencak silat di SMK Bina Insan Mandiri pada umumnya dalam melakukan tendangan depan teknik nya masih kurang benar. Indikasinya adalah tendangan depan masih mengarah ke bawah atau mengarah ke kemaluan. Gerak kaki pada saat tendangan depan masih diayun dengan sedikit mengangkat lutut, berdasarkan ilmu biomekanika tendangan ini tidak efektif dan efisien. Maka perlu adanya latihan khusus agar tendangan depan menjadi lebih sempurna.

Untuk mengatasi masalah di atas kami melatih teknik tendangan menggunakan rintangan berupa kursi. Pada praktik nya siswa dilatih tendangan depan melintasi rintangan kursi yang akan memaksa siswa untuk mengangkat dan menekuk lutut sebelum menendang. Latihan ini merupakan mengacu pada latihan keterampilan gerak yang sangat penting untuk pengembangan dan penghalusan program gerak dan mengurangi variabilifasnya dan latihan itu harus dirancang agar memudahkan pemerosesan informasi dan memindahkan para siswa ke tahap otomatis belajar keterampilan gerak (Juliantine, 2012). Rintangan kursi merangsang tumbuh nya pemahaman (proses informasi) bagaimana tendangan depan di lakukan, serta mengupayakan terjadi peningkatan ke tahap berikutnya yaitu tahap otomatis. Latihan ini selain melatih teknik tendangan depan juga melatih keseimbangan pada saat menendang. Untuk dapat melakukan tendangan depan dengan benar, maka harus 
menguasai kemampuan setiap gerakan nya dari sikap awal, pelaksanaan, perkenaan kaki, dan sikap akhir.

Untuk memperoleh teknik tendangan depan yang baik diperlukan latihan secara berulang-ulang dengan memperagakan gerakan tendangan depan yang benar sehingga menjadi kebiasaan. Latihan juga perlu dilakukan secara bertahap mulai dari latihan tanpa alat hingga dengan alat merujuk pada kemampuan motorik siswa. Latihan tanpa alat bertujuan membiasakan kebenaran gerakan tendangan siswa (Chaniago \& Harianto, 2018).

Latihan tendangan ke atas kursi juga berkaitan dengan psikologis siswa. kursi sebagai rintangan menjadi tantangan tersendiri bagi siswa untuk dilalui. Karena tantangan ini berada pada level sedang yang berarti tidak terlalu mudah dan juga tidak terlalu sulit, secara teori akan berdampak pada bangkit nya motivasi dalam berlatih. $\mathrm{Hal}$ ini karena penggunaan alat bantu dalam pembelajaran tendangan depan pencak silat dapat menumbuhkan rasa senang dan motivasi belajar siswa meningkat (Mursidi, 2012). Latihan ini juga berkaitan dengan variasi latihan yang bisa diubah-ubah rintangannya. Latihan yang bervariasi ini dapat memberikan motivasi untuk berlatih (Alhinduan et al, 2018). Dengan bangkit nya motivasi belajar akan memberikan peluang siswa untuk tetap berlatih dalam waktu yang optimal.

Selanjutnya latihan tendangan ke atas kursi juga berkaitan dengan proses pembelajaran gerak yang harus dilakukan secara bertahap dari mulai pemahaman bagaimana tendangan depan itu dilakukan. Setiap fase dalam tendangan depan harus dipraktikkan secara benar. kegiatan latihan tersebut akan memberikan pengalaman belajar siswa pada teknik tendangan depan, sehingga dapat memperbaiki dan meningkatkan kemampuan tendangan depan pencak silat (Suryadin \& Radiko, 2020).

\section{Metode Penelitian}

Metode penelitian yang digunakan dalam penelitian ini adalah metode eksperimen. Adapun desain nya Pre-Experimental Desain dalam bentuk one group pretest posttest. Pada desain ini terdapat pretest sebelum diberi perlakuan. Dengan demikian hasil perlakuan dapat diketahui lebih akurat, karena dapat dibandingkan dengan keadaan sebelum perlakuan (Sugiyono, 2018). Dalam penelitian ini peneliti melakukan tes awal (pretest) tendangan depan kemudian memberi perlakuan berupa 
latihan tendangan depan ke atas kursi yang diatur sedemikian rupa sehingga ketinggian rintangan nya dinaikkan secara bertahap, selanjutnya dilakukan tes akhir (posttest) untuk mengetahui perubahan nya. Perlakuan diberikan sebanyak 16 kali pertemuan dengan jumlah pertemuan 3 kali per minggu.

Dalam penelitian ini populasi nya adalah seluruh peserta didik yang terlibat dalam ekstrakurikuler pencak silat di SMK Bina Insani Kabupaten Cirebon. Yang berjumlah 16 siswa yang terdiri dari 5 siswa perempuan dan 11 siswa laki-laki. Teknik pengambilan sampel yang dipilih adalah teknik total sampling atau dinamakan sampel jenuh yang artinya seluruh populasi dijadikan sampel penelitian. Teknik penentuan sampel bila semua populasi digunakan sebagai sampel (Sugiyono, 2018).

Pengumpulan data dilakukan sebanyak dua kali yaitu pada saat tes awal dan tes akhir dengan menggunakan instrument berupa tes keterampilan tendangan depan yang diadaptasi dari (Lubis \& Wardoyo, 2013). Adapun indikator yang menjadi acuan dalam penilaian keterampilan tendangan nya ada pada tabel 1. Peralatan yang digunakan sabuk, tali meteran dan hanbok. Tata cara pengetesan adalah peserta didik bersiap-siap berdiri di belakang sabuk dengan jarak $60 \mathrm{~cm}$ (putri) dan $90 \mathrm{~cm}$ (putra) secara horizontal dan dengan ketinggian $75 \mathrm{~cm}$ (putri) dan $100 \mathrm{~cm}$ (putra). Kemudian melakukan tendangan di tempat di mana teknik tendangan depan harus melewati sabuk/tali tanpa menyentuh. Setiap atlet melakukan tendangan depan dapat dilakukan 3 kali dan diambil nilai tertinggi. Penilaian atau pemberian skor berdasarkan kisi-kisi instrumen seperti dijelaskan sebelumnya. Apabila ada salah satu indikator tidak dilakukan maka pada indikator tersebut tidak diberi skor. Misalnya atlet tidak seimbang ketika menendang maka di indikator keseimbangan skor nya 0 .

Tabel 1.

Instrumen Pengukuran Penampilan Keterampilan Pencak Silat

\begin{tabular}{clc}
\hline NO & \multicolumn{1}{c}{ INDIKATOR TENDANGAN DEPAN } & SKOR \\
\hline 1 & Posisi sikap pasang (awal) & 1 \\
\hline 2 & Lutut diangkat terlebih dahulu & 1 \\
\hline 3 & Posisi badan saat angkat kaki dalam keadaan & 1 \\
\hline
\end{tabular}




\begin{tabular}{llc}
\hline NO & \multicolumn{1}{c}{ INDIKATOR TENDANGAN DEPAN } & SKOR \\
\hline \multicolumn{3}{c}{ seimbang } \\
\hline 5 & Melepaskan kaki dengan keadaan lurus & 1 \\
\hline 5 & $\begin{array}{l}\text { Posisi badan saat lepasan kaki dalam keadaan } \\
\text { seimbang }\end{array}$ & 1 \\
\hline 7 & Posisi kedua tangan merapat dengan badan & 1 \\
\hline 8 & Menarik kaki dengan lutut merapat & 1 \\
\hline 9 & Posisi badan saat lutut merapat seimbang & 1 \\
\hline 10 & Posisi kedua tangan di depan dada & 10 \\
\hline Jumlah & Kembali kesikap pasang dalam keadaan seimbang & 1 \\
\hline
\end{tabular}

Analisis data menggunakan uji paired sample $t$ test dengan bantuan aplikasi komputer SPSS versi 21.

\section{Hasil dan Pembahasan}

Bagian ini akan disajikan data penelitian latihan tendangan ke atas kursi terhadap keterampilan tendangan depan siswa di SMK Bina Insani. Pada tabel 2 menyajikan nilai mean, standar deviasi, varian, nilai minimum dan nilai maksimum dari keterampilan tendangan depan.

Tabel 2

Deskripsi Statistik

Keterampilan Tendangan Depan SMK Bina Insani

\begin{tabular}{lcclll}
\hline & Minimum & Maximum & Mean & Std. Dev. & Variance \\
\hline Tes Awal & 2 & 7 & 4.69 & 1.352 & 1.829 \\
Tes Akhir & 7 & 10 & 8.81 & 1.047 & 1.096 \\
\hline
\end{tabular}

Berdasarkan tabel 2 di atas data keterampilan tendangan depan siswa SMK Bina Insani pada tes awal diperoleh data rata-rata sebesar 4,69 standar deviasi 1,352, dengan nilai varian 1,829, sebagai tambahan diperoleh juga nilai minimum 2 dan nilai maksimum 7. 


\section{Journal Respecs \\ Research Physical Education and Sports}

Vol.3, No.2, Juli 2021, pp. 45-52

Sedangkan pada tes akhir diperoleh data rata-rata sebesar 8,81 standar deviasi 1,047, dengan nilai varian 1, 096, sebagai tambahan diperoleh juga nilai minimum 7 dan nilai maksimum 10 .

Selanjutnya Dari data tabel 3 diperoleh gambaran pengujian hipotesis terjadi peningkatan sebesar 4,125, dengan standar deviasi 0,719. nilai Sig. (2-tailed) diperoleh nilai 0.000 dan nilai alpha 0,05 . Oleh karena nilai sig lebih kecil dari nilai alpha $(0,000$ $<$ 0.05). Artinya terdapat pengaruh latihan tendangan ke atas kursi terhadap keterampilan tendangan depan pada ekstrakurikuler pencak silat di SMK Bina Insan Mandiri.

Tabel 3.

Uji Hipotesis

Keterampilan Tendangan Depan SMK Bina Insani

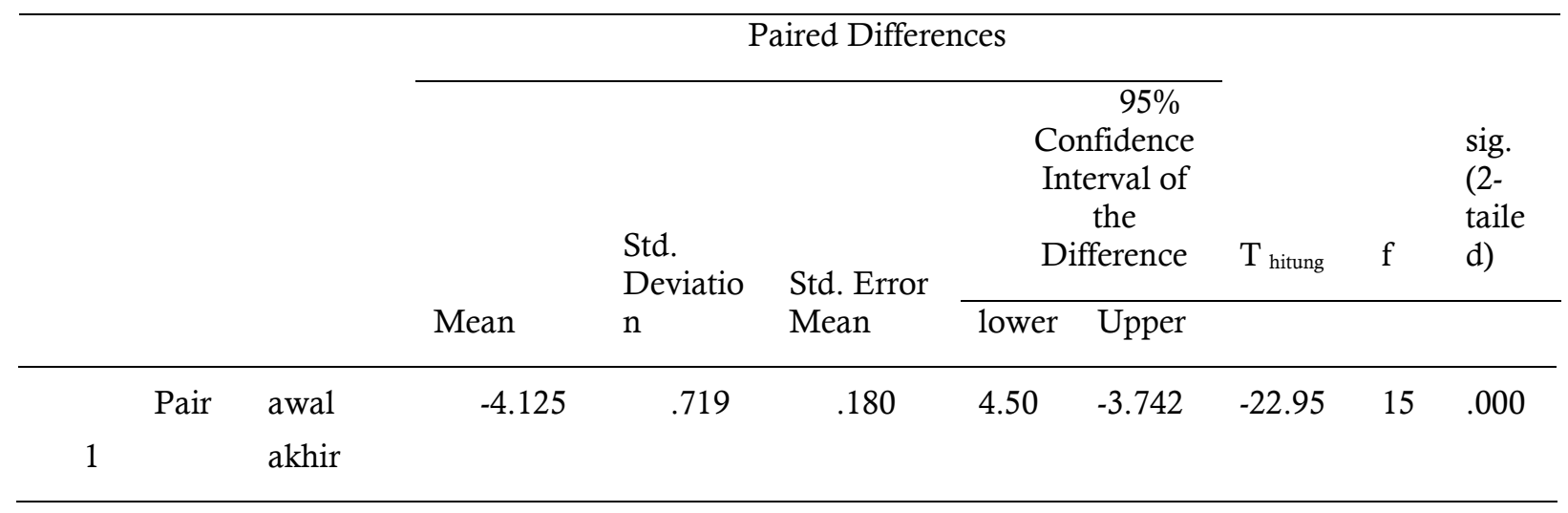

Pelaksanaan latihan tendangan ke atas kursi dilakukan secara bertahap, dari mulai kursi yang ditidurkan sampai kursi tersebut di dirikan. Hal tersebut dilakukan menggunakan prinsip latihan ditingkatkan secara progresif (meningkat).

Berdasarkan pengamatan peneliti selama penelitian, siswa yang mengikuti program latihan tendangan ke atas kursi terlibat dalam latihan yang mengandung tantangan, dampaknya siswa tidak menganggap enteng akan tetapi juga bisa memacu motivasi berlatih. Kursi sebagai rintangan menjadi tantangan tersendiri bagi siswa untuk dilalui. Karena tantangan ini berada pada level sedang yang berarti tidak terlalu mudah dan juga tidak terlalu sulit, proses yang seperti ini ternyata berdampak pada bangkit nya motivasi dalam berlatih.

Selanjutnya latihan tendangan ke atas kursi juga berkaitan dengan perbaikan teknik tendangan depan. Siswa dipaksa untuk mengangkat dan menekuk lutut lebih 


\section{Journal Respecs \\ Research Physical Education and Sports}

Vol.3, No.2, Juli 2021, pp. 45-52

p-ISSN: 2654-5233

e-ISSN: 2654-7112

tinggi, hal ini sejalan dengan prinsip-prinsip biomekanika untuk efisiensi gerak menendang. Setiap fase gerakan menendang dinaikkan tantangan nya secara bertahap. Hal ini merujuk pada prinsip-prinsip dalam membuat tujuan latihan gerak yaitu mengacu pada kunci dari elemen kesuksesan dalam membuat tujuan latihan gerak yaitu menantang (Challenging), bisa dicapai (Attainable), realistis (Realistic) dan spesifik (Specific) (Schmidt \& Wrisberg, 2000).

Latihan tendangan ke atas kursi juga berkaitan kepraktisan dalam penyediaan sarana dan prasarana latihan. Pada tahap awal latihan tendangan depan pelatih belum memerlukan penggunaan sarana latihan yang lain misalnya handbaox. Serta kursi mudah didapatkan dalam jumlah yang memadai di lingkungan sekolah. Hanya yang perlu diperhatikan adalah penempatan posisi kursi (berdiri atau direbahkan), serta ketinggian nya, sehingga bisa memberikan tantangan yang bisa dilalui oleh siswa. sebagaimana dipaparkan di atas hal ini berkaitan dengan menjaga motivasi siswa selama berlatih.

Berdasarkan paparan di atas, terbukti pada penelitian ini dimana nilai rata-rata siswa meningkat sebesar 4,125, dan setelah pengujian secara statistik bisa disimpulkan bahwa latihan tendangan ke atas kursi bisa meningkatkan keterampilan tendangan depan pada siswa ekstrakurikuler pencak silat di SMK Bina Insan Mandiri.

\section{Kesimpulan}

Terdapat pengaruh latihan tendangan ke atas kursi terhadap keterampilan tendangan depan pada ekstrakurikuler pencak silat di SMK Bina Insan Mandiri.

Berdasarkan penelitian ini penulis menyarankan kepada para praktisi yang menggeluti latihan pencak silat agar memperhatikan teknik-teknik dasar pencak dalam proses latihan nya.

\section{Daftar Pustaka}

Alhinduan, M. Hasan. dkk. 2018. Pengaruh Latihan Menggunakan Media Kursi Terhadap Tendangan Mawashi Geri Beladiri Karate.: Pontianak FKIP UNTAN.

Chaniago, Fandy Alfian. dan Harianto, Eko. 2018. Pengembangan Pembelajaran Teknik Dasar Tendangan T Untuk Siswa Ekstrakurikuler Pencak Silat PSHT Tingkat SMA.: Malang. Jurnal Gelanggang Pendidikan Jasmani Indonesia. 
Juliantine, Tite. dkk. 2012. Belajar dan Pembelajaran Penjas. Bandung: FPOK Universitas Pendidikan Indonesia.

Lubis, Johansyah dan Hendro Wardoyo. 2014. Pencak Silat Paduan Edisi Kedua. Jakarta: PT. Raja Grafindo Persada.

Mursidi, Ali. 2012. Meningkatkan Hasil Belajar Tendangan Depan Dalam Pencak Silat Melalui Penggunaan Alat Bantu Pembelajaran pada Siswa Kelas VII A SMP Muhammadiyah 2 Masaran Sragen Tahun Pelajaran 2011/2012.: Surakarta. FKIP Universitas Sebelas Maret

Schmidt, Richard A. dan Wrisberg, Craig A. 2000. Motor Learning and Performance. Second Edition. Human Kinetics

Sugiyono. 2018. Metode Penelitian Kuantitatif Kualitatif dan $R \& D$. Bandung: CV Alfabeta.

Suryadin, Tatang dan Radiko. 2020. Pengaruh Penerapan Media Pembelajaran Video Tutorial Terhadap Peningkatan Kemampuan Teknik Dasar Tendangan Depan Pencak Silat.: Majalengka. Jorrnal Respecs FKIP UNMA.

Widianto dan Hariono. 2014. Analisis Gerak Teknik Tendangan Depan Atlet Pencak Silat PPLM DIY (Sebuah Kajian Biomekanika Olahraga). Jurnal Seminar Olahraga Nasional (hlm. 26-44). Yogyakarta: Universitas Negeri Yogyakarta. 